\title{
Helen Salisbury: The informed patient
}

\author{
Helen Salisbury GP \\ Oxford
}

Shame, guilt, and apology abound in the GP consultation as people describe their failures to lose weight, give up smoking, or restrict their use of alcohol or other drugs. The language we use to talk about health status can compound these negative feelings.

"Good" and "bad" are used to describe levels of blood sugar, cholesterol, or blood pressure. It's very easy for those words to be interpreted beyond their intended scope, so that the patient whose diabetes is difficult to control feels judged and found wanting.

But the apology I find the most surprising is when patients "admit" to having informed themselves about their symptoms or illness. "I'm sorry doctor, I know I shouldn't ..." they start, apologising for what's surely the most obvious response to an unfamiliar symptom-looking it up online. In earlier days, did patients feel similarly sheepish about consulting a copy of a Family Medical Guide before seeing their doctor?

Admittedly, there are risks: searches about the most innocuous of symptoms can lead down a terrifying rabbit hole to a terminal diagnosis within minutes (I just checked: hiccups can be a symptom of liver cancer). However, there are many reliable and balanced sources of information, and people increasingly seem to be able to find them.

The most surprising apology is when patients 'admit' to having informed themselves about their symptoms or illness

The root of the apology seems to be a fear of being disrespectful, ${ }^{1}$ as if by consulting another source of information the patient is casting aspersions on my expertise. It speaks of an old fashioned relationship between patient and doctor-the supplicant and the dispenser of wisdom, where the former feels as though they are stepping out of role or even overstepping the mark by offering their own ideas or research findings. A few doctors may even perpetuate this, feeling their authority threatened by the informed patient and closing down any discussion of what's been learnt from "Dr Google."

By contrast, the relationship I'm aiming for is a meeting between equals, working together to solve a problem. If we can achieve this the potential for the internet to empower patients is huge. Often, patients will have arrived at a sensible conclusion that's based on their symptoms and family history, which makes our consultation that bit more efficient. Even if a patient has found something frightening but unlikely, as long as I discover this fear I can explain and reassure.

As doctors it's imperative that we find a way to ask, "What have you found out so far?" Given an opportunity to share, we can together reconcile conflicting explanations of the symptoms. Without that conversation, the patient may leave still fearful of the web based, worst case scenario.

Competing interests: I am a GP partner, I teach medical students at Oxford University and St Anne's College, Oxford, and I answer readers' medical problems for Take A Break magazine. I am also a member of the National Health Action Party and serve on its national executive committee.

Provenance and peer review: Commissioned; not externally peer reviewed.

Tan SS, Goonawardene N. Internet health information seeking and the patient-physician relationship: a systematic review. J Med Internet Res 2017;19:e9. 10.2196/jmir.5729. 28104579

Published by the BMJ Publishing Group Limited. For permission to use (where not already granted under a licence) please go to http://group.bmj.com/group/rights-licensing/ permissions 